\title{
DISTURBANCES OF THE RESPIRATORY RHYTHM IN CHILDREN
}

\author{
A SEQUELA TO EPIDEMIC ENCEPHALITIS
}

HARRY L. PARKER, M.B. (University of Dublin)

Fellow in Neurology, the Mayo Foundation; First Assistant in Section on Neurology, Mayo Clinic

ROCHESTER, MINN.

The manifestations of epidemic encephalitis in children have received attention in this and other countries, and it has been our privilege in the Mayo Clinic to see nearly all the features described by other observers. However, one syndrome in children, which was presented to us more forcibly than the other more common disturbances of function, was a disturbance of the respiratory rhythm and depth, persisting many months after the initial phase of the disease had passed. Seven children and one adolescent came to the Mayo Clinic during the last half of 1921 and the first half of 1922, manifesting, besides the characteristic disturbance of the respiratory function, the now well recognized intractable insomnia and metamorphosis of character seen in children who have had epidemic encephalitis. Six of the patients dated their illnesses from the first three months of 1920 .

Disturbances in respiration during the acute stages of encephalitis. have already been described by Happ and Mason; ${ }^{1}$ six of their eightyone patients had marked hyperpnea during the early part of their illness. In the 115 cases analyzed by Dunn ${ }^{2}$ there were three patients who had hyperpnea lasting for a few days. Epidemic hiccup was a. form of respiratory disturbance associated with encephalitis, and later events showed that hiccup might be the sole manifestation of an abortive type. Sicard and Paraf ${ }^{3}$ reported the cases of a series of patients who had suffered from various paroxysmal respiratory disturbances in the form of hiccup, yawning, stretching, sobbing and uncontrollable laughing. Aronson ${ }^{4}$ observed a boy, aged 8, who during his convalescence from encephalitis had developed a protracted hyperpnea which had lasted for seven weeks. Hass described the respiratory

1. Happ, W. M., and Mason, V. R.: Epidemic Encephalitis. A Clinical Study, Bull. Johns Hopkins Hosp. 32:137, 1921.

2. Dunn, A. D., and Heagey, F. W.: Epidemic Encephalitis: Including a Review of 115 American Cases, Am. J. Med. Sc. 160:568-582, 1920.

3. Sicard and Paraf: Fourire syncopale et baillements au cours de l'encephalite epidemique, Bull. et mém. Soc. méd. d. hôp. de Paris, 45:232-234, 1921.

4. Aronson, L. S.: Encephalitis with Unusual Sequelae, Neurol. Bull. 3:$113,1921$. 
disturbance of a child, aged 2 years, who, without any initial febrile episode, developed insomnia and change of olaracter. The child suffered from attacks of forcible breathing followed by breath holding, cyanosis and unconsciousness. She had had as many as six attacks in one hour. In recent literature cases of disturbed respiration and bizarre performances have been reported.

In nearly all our patients the initial febrile attack was mild; the more severe symptoms followed later in some cases. This is in accord with the experiences of others, Marie and Levy ${ }^{5}$ in particular, who gave the name of tardy encephalitis to this type of the disease. The persistency of the syndrome following so slight an onset left, however, no doubt with regard to the nature of the disease. It seems characteristic of the disease in children that the onset is mild, but the sequelae are none the less severe.

\section{REPORT OF CASES}

CASE 1.-C. P., a thin undernourished boy, aged 14, was brought to the Clinic, May 9, 1921. In January, 1920, he had suffered from pains along the left sciatic nerve, followed by myoclonic jerking of the left lower extremity. Marked insomnia, polyuria and polydipsia had developed, and he had become dull and had lost interest in his studies. Later the right side of his body had become slow, stiff and clumsy. In May, 1921, grunting expirations had developed, and later stretching and bending motions of the trunk and limbs. These had persisted and insomnia had increased.

During a paroxysm the child suddenly rose from his seat and stretched his body so that his back was strongly curved forward and his abdomen protuberant. His chin usually was sunk on his chest and his arms rotated outward in the attitude of an early morning stretch and yawn. He held his breath in this position for about twenty seconds, then dropped back on the seat, thrust his head between his knees, and in a doubled position released his breath in a series of coughing grunts. These attacks might be repeated again and again day and night; in fact, the boy scarcely slept (Fig. 1). The boy had definite nystagmus, horizontal and vertical, loss of speed, and clumsiness in his whole right side. He had a bilateral Babinski sign and definite parkinsonian facies, gait, and posture. He drooled saliva, and he had slight dysarthria and tremor of both hands.

While the child was under observation for two months, the movements were continued and all sorts of therapy including hypnosis yielded no positive results. He was dismissed somewhat improved, but two months later his parents reported that he was as bad as before.

CASE 2.-O. K., a girl, aged 12, was brought to the Clinic, Jan. 18, 1922. In March, 1920, she had had what was diagnosed as influenza and had been in bed for four days with a high temperature, headache and general malaise. Marked insomnia with choreiform movements followed; her disposition changed, and she became impulsive, stubborn and disobedient. Often during 1920 she had stayed up all night at her studies, but had made less progress than before. In the first few months of 1921, she began to breathe noisily and rapidly, and

5. Marie, P., and Levy, G.: Le syndrome excito-moteur de l'encephalite epidemique, Rev. neurol. 36:513-539, 1920. 
she later supplemented this with breath-holding attacks in which she stood erect with her head thrown back. By the end of 1921, these attacks became so severe that she lost consciousness at the end and fell, hurting herself on more than one occasion. The attacks often occurred at night, and the patient had to be watched to prevent serious injury.

During an attack the girl suddenly stood erect in the "attention" position with chest fully inflated, head thrown back, arms stiffly at her sides, and hands clinched. She held her breath in this position for from twenty to thirty seconds and became cyanosed, so that when she finally released her breath she staggered or fell, breathing noisily in deep quick pants (Fig. 3). After a few seconds, the head jerked quickly backward again. This was continued until the child became dull and stupid, and sat down unsteadily, breathing imper-

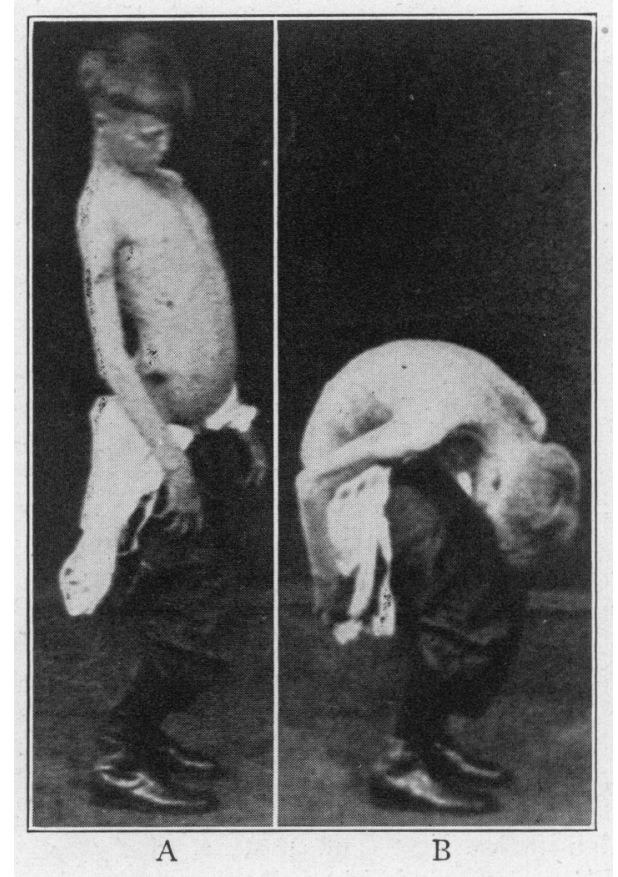

Fig. 1 (Case 1). $-A$, attitude of patient at the height of the respiratory phase; complete cessation of breathing for twenty seconds; $B$, attitude at the end of the expiratory phase. The patient is releasing his breath in a series of coughing grunts.

ceptibly. Later the attacks were repeated for an indefinite period. In intervals between attacks the child breathed noisily, and was disobedient, impulsive and explosive in her speech. She is still under observation and has shown no improvement.

CASE 3.-M. C., a girl, aged 2 years and 10 months, was brought to the Clinic, Sept. 14, 1921. After an attack of tonsillitis in January, 1920, she had slept badly, had become backward in development, had ceased to talk or play with other children, and was irritable, fretful and peevish. June, 1920, she awoke one night and went into a series of breath-holding attacks, but the 
next day she seemed as usual; wery night thereater these attachs were resumed. Two months before, the attacks had occured during the day as well. All correction or admonition was useless; even beating during an attack was of no avail, as she did not secm to feel the hlows. A few days before, a continued series of attacks had wecured from midnight t:12til 11 p. $\mathrm{m}$.

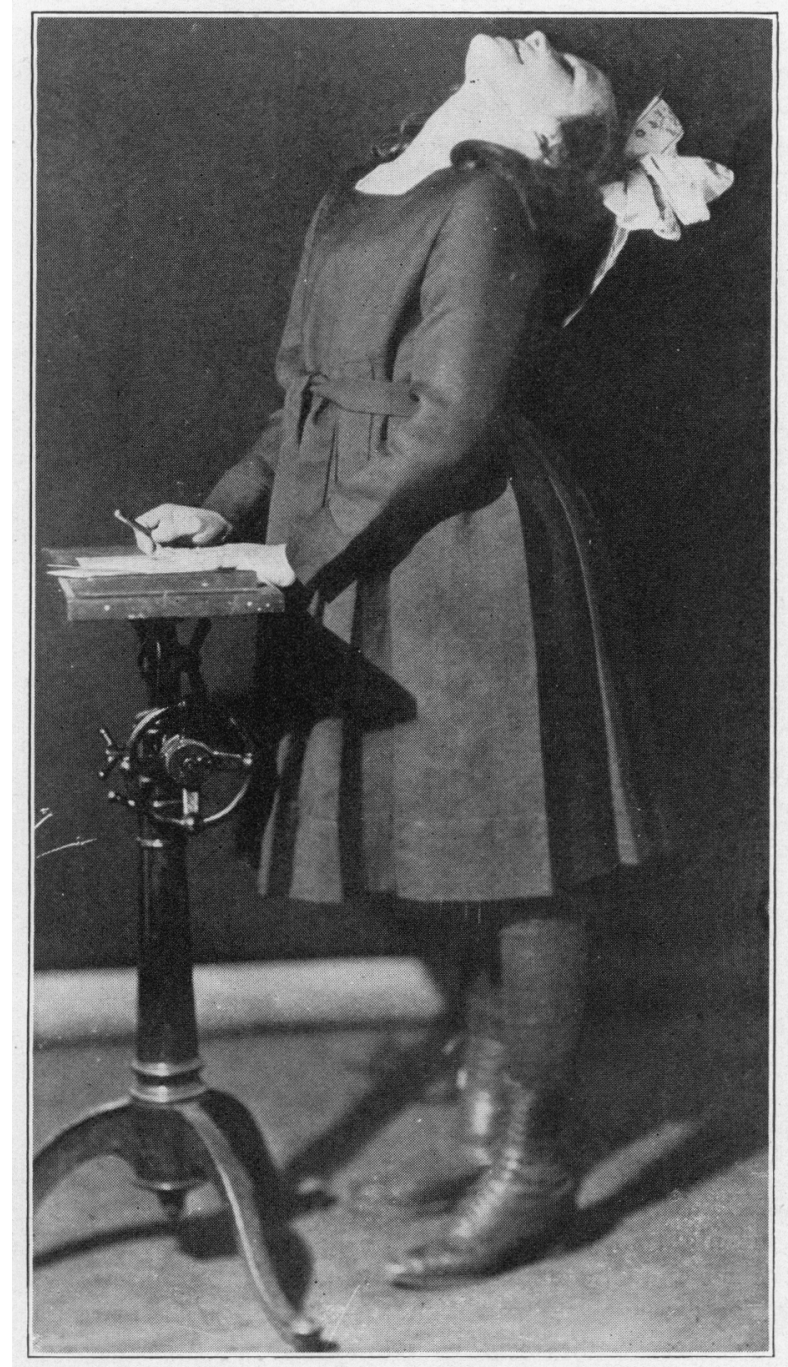

Fig. 2.-Attitude of patient during the height of the inspiratory phase. Fuil inspiration witl partial and slow escape of pent up breath through clenched teeth.

During an attack the child stoun on her cot and ceased breathing for from twenty to thirty seconds, then hent her hody far ower pressing her hands against her abdomen and giving exit to the pent up breath in a series of noisy grunts, terminating in a whining ery. She then hreathed noisily and ant until the next attack a few minutes later. 
She was isolated from her parents for thirty-six hours at a time and her noisy respiration and grunts could be heard all over the floor on which her room was situated. The attacks seemed independent of emotion; they occurred when the child was apparently quiet and satisfied with her surroundings. She slept scarcely at all and the persistency of her performances was a wonder to all beholders. She was dismissed unimproved, although all reasonable forms of therapy were tried.

CASE 4,-J. L., a boy, aged 12 years, was brought to the Clinic, Feb. 24, 1921. In January, 1920, he had had what was diagnosed as influenza, which was characterized by high temperature, malaise and headache, lasting a few weeks. From that time he had slept badly. Five months later, he had developed attacks of breath-holding with noisy respirations. These attacks usually occurred at night and had persisted up to the time of examination.

During an attack the boy usually stood, took a deep breath, held it with his chin depressed on his chest and waved his arms around irregularly. After fifteen seconds he rubljed his abdomen, released his breath, and fell over on his right side. On one occasion ten attacks occurred in five minutes.

During observation of the boy in the hospital for twelve days he was quiet and well behaved. He repeatedly promised to try to control his attacks, but as soon as the promise was given he went off into another series. He slept badly, and the attacks continued night and day. He was dismissed, little improved.

CASE 5.-R. J., a boy, aged 10 years, was brought to the Clinic, July 23, 1921. In November, 1920, he had had what was diagnosed as measles, after which he had become restless and fidgety and had slept badly. A few weeks later, he had begun to have respiratory difficulty during which he had attacks of breath-holding. In December, 1920, he had had a general epileptiform convulsion in his sleep. In January, 1921, just after tonsillectomy, his disposition had changed; he had become rebellious, irritable and intolerable, and attacks of breath-holding continued night and day with little rest.

During an attack the boy suddenly jumped from the place on which he was seated and jumped up and down on his toes, passing his hands through his hair, with his breath held in full inspiration. A few seconds later he released his breath, belched a few times, and sat down. His face twitched in a haphazard manner toward the end of the performance.

In the hospital the child was tied down and isolated; nevertheless he went through a modification of his attack with breath-holding. He was noisy and sleepless and intensely irritable. Communications after his dismissal showed that in October, 1921, he had improved and was only having one attack a week.

CaSe 6.-R. H. T., a boy, aged 6 years, was brought to the Clinic, November, 1921. One night in January, 1920, he had become restless and had slept badly. In the morning he had definite internal strabismus. His temperature had been 100 for a few days, and then the strabismus had disappeared; from then on he had slept badly, and his character had markedly changed. He sang and whistled all night and slept little during the day. A year before he had developed constant noisy breathing and breath-holding attacks. A few months before, he had begun to fall unconscious, rising, however, almost immediately.

The boy was impulsive, noisy, restless and very aggressive. $\mathrm{He}$ panted loudly and from time to time held his breath, became cyanosed, and fell unconscious for a fraction of a minute. Moreover, he often fell down when not holding his breath. He had to be strapped in bed to prevent his falling 
out, as when unrestrained he invariably stood to breathe noisily and hold his breath, often toppling over at the climax of the performance. He went into bursts of passion for no adequate reason, was abusive, used bad language and attacked the nurses and physicians with feet and fists. In spite of this he was fairly intelligent. When asleep he breathed normally, but he seldom slept. The combination of an excitable, pugilistic manner, gusty, loud breathing and incessant chatter characterized his daily appearance. He was under observation for four months and was dismissed somewhat improved but liable to relapse under emotional influences.

CASE 7.-Miss M. G., a music teacher, aged 20 years, came to the Clinic, Nov. 16, 1921, complaining of drowsiness and difficulty in breathing. In February, 1920, she had had what was diagnosed as influenza. She had been ill for six weeks with moderate fever, diplopia, blurred vision and marked lethargy and prostration; this lethargy had persisted so that recently she slept from 8 p. m. until 9 a. m., and often for some hours during the day; she had extreme difficulty in remaining awake. She felt great discomfort when standing erect

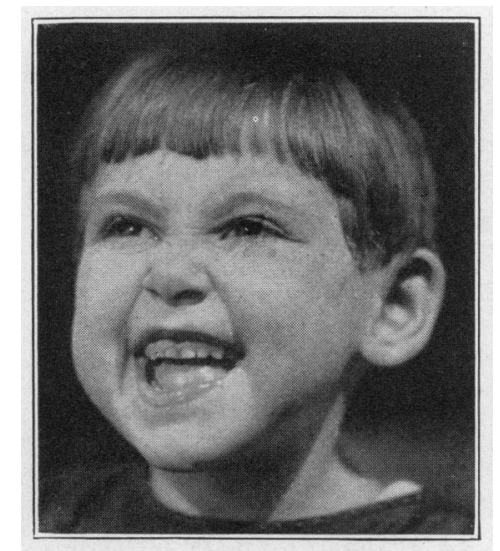

Fig. 3 (Case 8),-General expression of the patient.

or undergoing moderate exertion because of intolerable dyspnea. She spent most of her time recumbent and avoided any exertion. She had gained 20 pounds $(9.07 \mathrm{~kg}$.) since her illness.

Respiration and pulse rates varied with sitting, standing and prone positions. When the patient was recumbent and at complete rest, her pulse rate averaged 75 and her respiration 14; when standing or with the slightest exertion, her respirations increased to 30 or 40 , her pulse became uncountable, her face became flushed, and all the accessory muscles of respiration, especially the sternocleidomastoids, stood out prominently. There was a parkinsonian appearance in her gait, facies and posture, and she had definite tremor of the hands.

CASE 8.-D. F., a child, aged 4 years, was brought to the Clinic, April, 1922. She had had influenza in the spring of 1919 , after which she ceased to walk, became backward in development, irritable and noisy, and slept badly. She forgot all speech she had learned; a few months later she began to walk again unsteadily and clumsily. There was little change and no development of mental faculties from the age of 12 months until examination. In March, 
1922, she again had a febrile attack associated with cough and malaise. She was ill four days with a temperature of $104 \mathrm{~F}$., and thereafter again ceased to walk. On the last day of her illness she suddenly began to breathe noisily and rapidly and at night had attacks of breath-holding. She began to slobber saliva and developed a habit of constantly sucking three fingers of her right hand.

The child was obviously unintelligent. While observed, without any display of emotion, she puffed away noisily, commencing with a period of apnea and then breathing faster and louder until a climax was reached, after about thirty respirations, when she made a grimace (Fig. 3), held her breath for almost fifteen seconds and made athetoid movements with her hands. She then usually released her breath, waved her arms around aimlessly and panted loudly. This gradually diminished until a period of apnea was reached, when the cycle was again and again repeated for as long as she was under observation. She was dirty in her habits, and unable to walk. Her lower limbs were spastic. She hardly used her left side, and on this side Babinski's sign was positive. Her noisy respirations could be heard at a distance, and these only ceased when she ate and slept. She is still under observation.

\section{GENERAL CONSIDERATIONS}

Complete physical, neurologic, and laboratory studies were made in most of the cases, with no more positive results than those mentioned. Attempts to substantiate the suggestion of tetany in a few of the patients by means of blood examination and electrical reactions were unsuccessful. Our first impression of these patients was that their individual performance was a functional disorder of hysterical nature, and the treatment was directed accordingly. As patient after patient showing the same characteristics arrived within a relatively short time, the disease assumed an epidemic character, and we had to seek a different diagnosis. Reviewing the individual histories, we discovered that these patients nearly all dated their illness from the first three months of 1920 and, moreover, some of them had had an initial illness, definitely encephalitic, and some had evidence of gross cerebral damage (Cases 1,7 and 8). Eventually we had little doubt with regard to the nature of the disease, and its persistency and failure to respond to ordinary therapeutic measures confirmed the diagnosis.

There was a marked resemblance in the paroxysmal disturbances of respiration in the first five patients. Essentially their syndrome consisted of assuming the erect posture, breathing noisily, holding the breath with bodily contortions and releasing the breath in a position best suited for complete expiration.

Cyanosis with partial loss of consciousness, falling, and petit mallike attacks were common and present in three cases, and all the patients had the marked insomnia and metamorphosis of character so well described by earlier observers.

The only adult of the series (Case 6) had a syndrome observed in no other patient. In many ways her condition resembled that of an 
animal with both vagi cut. She had no respiratory reserve to draw on; at rest she was comfortable, but her breathing was always maximal in depth, and exertion could not be tolerated.

Localization of the lesion is a matter of speculation; probably a diffuse process was present. Case 6 was the only one in which one dared to postulate a location of damage as in or around the respiratory center in the medulla.

Endeavor was made to investigate the psychologic mechanism of these patients. Their emotional, rebellious manner was against them, and at times it seemed as if their performances were gone through wilfully, that they themselves could end them if they wished. It seemed that all that was needed was some stern discipline and isolation to produce an amelioration. We soon found out our mistake, as neither of these measures, or any others had the slightest effect. Hypnotism was ineffectual, and direct questioning as to why they went through their movement produced the reply: "Because I want to," or "Because I feel better when I do it."

The lengthy period of the illness, on the average eighteen months, was not more striking than the stereotyped character of the movements which were persisted in day and night with monotonous regularity. The patients were extremely difficult to manage and disturbed all around them.

Two patients, Cases 2 and 8 , have been seen recently; they have not improved. The future of the other six patients is as yet unknown; time alone will show whether they will recover and grow into normal adults. The epidemic of encephalitis provided many strange and bizarre pictures, but few surpassed the appearance of these little children at the height of their illness. It is a syndrome that has to be added to the kaleidoscopic picture of epidemic encephalitis.

\section{SUMMARY}

1. During the year 1921 eight patients, seven of whom were children, were under observation at the Mayo Clinic, suffering from a disturbance of the respiratory rhythm.

2. While four of the patients had had an infectious illness worthy of the diagnosis of epidemic encephalitis, the remaining patients dated their illnesses from an infectious episode or febrile illness. In seven patients the onset occurred cluring the first three months of 1920 .

3. The main features of the clinical picture in these cases were paroxysmal stretching, breath-holding, grunting and forced noisy respirations. In others there was constant dyspnea associated in one case with posture. 
4. The average duration of the illness was seventeen months before examination at the Clinic, and in a few cases there was an appreciable gap between the initial illness and the appearance of the prominent symptoms.

5. The perisistency of the symptoms contrasted with the peculiar nature of the disease which was more manifest by night than by day. It was relatively unaffected by various forms of therapy.

6. Combined with the peculiar paroxysmal respiratory attacks were changes in character. The patients were noisy, disobedient, and passionate, whereas formerly they had been well behaved. There was marked insomnia with inversion of the sleep rhythm in the seven children and abnormal drowsiness in the one adult. 